Luciana de Almeida LACERDA $^{1}$

Simone Tostes de OLIVEIRA ${ }^{1}$ Tatiana Amaral GUERRA ${ }^{1}$ Gisele Guiomara STEIN ${ }^{1}$ Félix Hilario Díaz GONZÁLEZ

\section{Correspondência para: \\ Laboratório de Análises Clínicas Veterinárias, Faculdade de Veterinária, Universidade Federal do Rio Grande do Su - Av. Bento Gonçalves, 9090 - 91540.000 - Porto Alegre, RS. \\ e-mail: luciana.lacerda@ufrgs.br}

Recebido para publicação: 13/06/2007 Aprovado para publicação: 07/03/2008

\title{
Prevalência dos tipos sangüíneos $A$, $B$ e $A B$ em gatos domésticos mestiços da cidade de Porto Alegre, Rio Grande do Sul, Brasil
}

\author{
1 - Laboratório de Análises Clínicas Veterinárias da Faculdade de Veterinária \\ da Universidade Federal do Rio Grande do Sul, Porto Alegre-RS
}

\section{Resumo}

O presente estudo teve como objetivo determinar a prevalência dos tipos sangüíneos em felinos domésticos, mestiços, da cidade de Porto Alegre, Rio Grande do Sul, Brasil. Foram selecionados aleatoriamente 100 gatos, clinicamente saudáveis, mestiços e sem parentesco entre si. Amostras de sangue foram coletadas da veia jugular e a tipagem sangüínea foi realizada através do teste RapidVet H Feline (DMS Laboratories, Flemington, USA) e do teste hemaglutinação em tubo de ensaio. A tipagem reversa foi realizada para confirmar o tipo e a presença de aloanticorpos naturais. No presente estudo encontrou-se prevalência de $97 \%$ e 3\% de gatos do tipo A e B, respectivamente. Não foram encontrados gatos do tipo $\mathrm{AB}$. Os resultados indicam que no sul do Brasil há uma alta prevalência de gatos domésticos mestiços do tipo A, entretanto a prevalência de gatos do tipo B encontrada no trabalho é mais alta do que aquelas relatadas em alguns países. O conhecimento da prevalência dos tipos sangüíneos da população de gatos de uma região pode auxiliar na determinação dos riscos de reações transfusionais e de ocorrência de isoeritrólise neonatal, e estes podem ser prevenidos através de tipagem sangüínea e teste de compatibilidade sangüínea.

\section{Introdução}

Os tipos sangüíneos são definidos por antígenos espécie-específicos presentes na superfície dos eritrócitos. A maior parte dos antígenos é um componente integral de membrana composto por carboidratos complexos associados a proteínas ou lipídeos inseridos na membrana eritrocitária. ${ }^{1}$ Os antígenos eritrocitários podem variar em imunogenicidade e significado clínico, sendo a sua detecção realizada através de testes sorológicos de aglutinação. $\mathrm{Na}$ medicina veterinária, o significado clínico dos tipos sangüíneos está associado às reações transfusionais e à isoeritrólise neonatal. ${ }^{2}$

Em felinos, a nomenclatura que designa os tipos sangüíneos A e B foi usada pela primeira vez em 1962. Um terceiro tipo AB foi descrito em 1980 e desde então não houve descrição de gatos que não possuíssem antígenos eritrocitários (tipo $\mathrm{O}$ ou nulo). Apesar do uso das mesmas letras aplicadas aos tipos sangüíneos humanos, não existe relação sorológica alguma entre o sistema $\mathrm{AB}$ felino e o $\mathrm{ABO}$ humano ${ }^{2}$. Além dos tipos que compõem o sistema $\mathrm{AB}$ felino, um outro tipo sangüíneo denominado "Mik" foi recentemente descrito nos Estados Unidos. ${ }^{3}$

Os tipos sangüíneos do sistema $\mathrm{AB}$ felino são determinados por pelo menos dois alelos $(\mathrm{A}, \mathrm{b})$ no mesmo locus. $\mathrm{O}$ alelo tipo A parece ser completamente dominante sobre o alelo b. Portanto, gatos com fenótipo A podem ter genótipo $\mathrm{A} / \mathrm{A}$ ou $\mathrm{A} / \mathrm{b}$, enquanto que somente gatos homozigotos para o alelo b (b/b) expressam quantidades suficientes do antígeno eritrocitário B e não possuem antígeno $\mathrm{A}$. Um terceiro alelo, $\mathrm{AB}$, que é recessivo em relação ao alelo $A$, mas dominante sobre o alelo B, ainda é estudado, mas acredita-se que seja determinante para 
a herança do tipo sangüíneo $\mathrm{AB} \cdot{ }^{4,5} \mathrm{~A}$ presença dos antígenos eritrocitários do sistema $\mathrm{AB}$ nos fetos felinos pode ser detectada aos 38 dias de gestação. Os gatos parecem não expressar um gene que determine a secreção destes antígenos, visto que os antígenos $\mathrm{A}$ e B não foram detectados na saliva destes animais. ${ }^{2,5}$

Pesquisas sobre a prevalência de cada tipo sangüíneo foram realizadas em diversos países e os resultados destes estudos possuem aplicação prática na clínica de pequenos animais. Se a compatibilidade sangüínea é completa, os eritrócitos do sangue transfundido têm uma vida média de quatro a cinco semanas. Por outro lado, se não há compatibilidade, as células podem durar apenas poucas horas, até alguns dias. Além disso, transfusões realizadas sem compatibilidade sangüínea podem levar a uma reação transfusional hemolítica imuno-mediada aguda severa, principalmente quando sangue de tipo A é transfundido em um gato tipo B, pois estes possuem altos níveis de aloanticorpos naturais. Nestes casos poucos mililitros de sangue são suficientes para causar uma reação que pode ser fatal. ${ }^{5} \mathrm{O}$ tipo $\mathrm{AB}$ não apresenta aloanticorpos contra $\mathrm{A}$ e $\mathrm{B}$, podendo receber sangue de ambos os tipos. Entretanto, devido ao fato de que gatos do tipo A e, principalmente, B podem apresentar altos títulos de aloanticorpos, pode ocorrer hemólise em gatos tipo $\mathrm{AB}$ quando recebem outro tipo de sangue. $^{2}$

O teste de compatibilidade e a tipagem sangüínea são exames essenciais antes de iniciar qualquer transfusão sangüínea. Vários laboratórios no mundo oferecem diferentes tipos de testes, cada vez mais modernos, para a tipagem sangüínea de felinos para atender a demanda veterinária. Os métodos incluem teste em tubo de ensaio, lâmina de microscopia, cartão com anticorpo policlonal ou monoclonal, gel e microtubos. Todos os testes se baseiam nos princípios de hemaglutinação, mas os reagentes e concentrações utilizados, a forma de leitura, a preparação da amostra e o tempo de realização do teste podem ser diferentes. O princípio de uma reação positiva de tipagem sangüínea sorológica é a visualização macroscópica da aglutinação de eritrócitos em pouco tempo, utilizando anticorpo conhecido ou um reagente especial com capacidade aglutinante. Se a aglutinação não é observada, o teste é considerado negativo. Os reagentes para tipagem podem ser anticorpos policlonais ou monoclonais, ou ainda lectinas. ${ }^{6}$

Estudos realizados em vários países demonstraram que o tipo sangüíneo A é o mais comum. Entretanto, observou-se que a proporção dos gatos tipo B varia significativamente conforme a região geográfica. A prevalência de gatos tipo B também varia muito entre raças, enquanto que gatos tipo $A B$ são raros. Os gatos tipo $A B$ têm sido encontrados somente quando existem gatos tipo B na população. Os tipos sangüíneos não foram associados com a coloração da pelagem..$^{5,7}$

O tipo sangüíneo A é o de maior prevalência em felinos domésticos, mas existem diferenças entre algumas raças (Tabela 1). As raças Devon Rex, Cornish Rex, Pêlo Curto Britânico, Exótico de pêlo curto, Van Turco, Angorá Turco, apresentam uma prevalência do tipo B bastante alta, com percentagens que variam de 30 a $60 \%$. Por outro lado, a raça Siamês e outras relacionadas com o Oriental de pêlo curto, assim como o Tonquinês, possuem exclusivamente tipo sangüíneo A. ${ }^{9,10,11,12}$ No Brasil, poucos animais de raças puras foram estudados. ${ }^{13,14}$

O conhecimento sobre os tipos sangüíneos de diferentes espécies é de grande importância na medicina veterinária, visto que uma transfusão sangüínea incompatível pode resultar em uma reação transfusional hemolítica imuno-mediada severa e até levar o animal à morte. ${ }^{2} \mathrm{O}$ objetivo do presente trabalho foi determinar a prevalência dos tipos sangüíneos de felinos domésticos mestiços da cidade de Porto Alegre, RS, Brasil.

\section{Material e Método}

Foram utilizados 100 gatos domésticos mestiços (36 machos e 64 fêmeas), com peso corpóreo maior que dois $\mathrm{kg}$, com idades variadas (um a 13 anos) e clinicamente saudáveis, de proprietários particulares da cidade de Porto Alegre/ RS. 
Tabela 1 - Prevalência dos tipos sangüíneos em gatos domésticos de raça em diferentes países

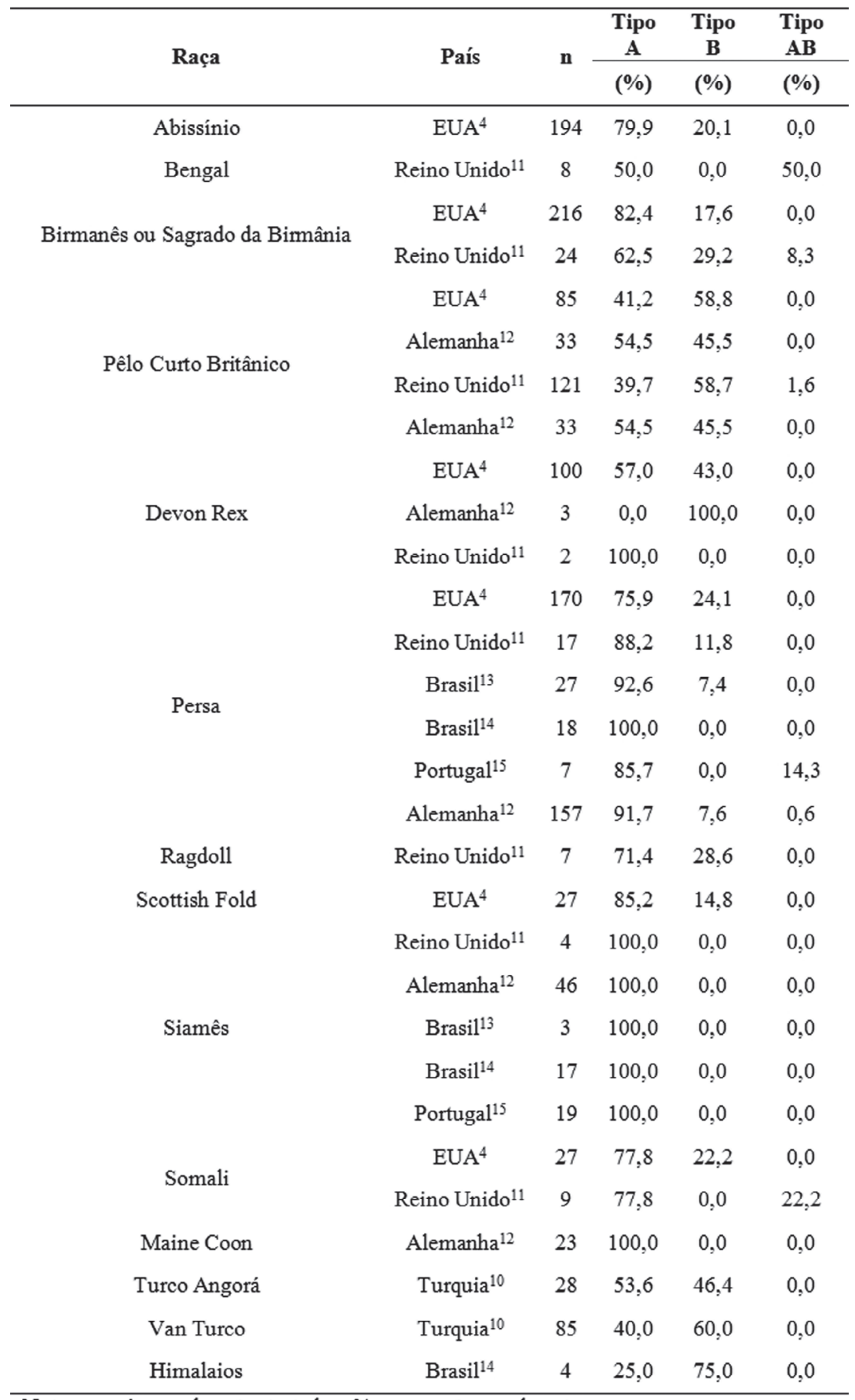

Nota: $\mathrm{n}=$ número de gatos testados; \% = porcentagem de gatos.

De cada animal foram colhidas, após antisepsia adequada, duas amostras de sangue (máximo de oito $\mathrm{mL}$ no total) por punção venosa jugular em tubos de três $\mathrm{mL}$ com ácido etilenodiaminotetracético dipotássico
(EDTA $K_{2}$ ) para a tipagem sangüínea e tubos de cinco $\mathrm{mL}$ sem aditivo para obtenção do soro para a tipagem reversa. Nenhum dos animais estava sob algum tipo de tratamento, histórico recente de doença grave ou havia 
recebido transfusão sangüínea prévia e, no caso das fêmeas, nenhuma estava prenhe.

As amostras de sangue para tipagem sangüínea foram mantidas sob refrigeração $\left(4^{\circ} \mathrm{C}\right)$ no máximo até 8 horas após a coleta. A tipagem foi realizada por meio de kits comerciais (RapidVet H Feline; DMS Laboratories, Flemington, NJ, USA). O teste de hemaglutinação em tubo de ensaio (Penn Animal Blood Bank, University of Pennsylvania, Philadelphia, USA) foi realizado nos casos de autoaglutinação, resultados suspeitos ou para confirmação de tipo $\mathrm{B}$ ou $\mathrm{AB}$.

A tipagem sangüínea em cartão foi realizada de acordo com o fabricante e um cartão individual foi utilizado para cada animal. A apresentação do produto consiste em um cartão apresentando três poços prédeterminados como: controle com solução salina (C), teste paciente tipo A contendo soro felino anti-A (A) e teste paciente tipo B contendo Triticum vulgaris, uma lectina de germe de trigo, que induz aglutinação de células tipo $\mathrm{B}(\mathrm{B})$. A técnica consistiu em colocar uma gota $(40 \mathrm{~mL})$ de solução PBS (solução tampão fosfato) em $\mathrm{C}$, adicionar $50 \mathrm{~mL}$ de sangue com EDTA e misturar com movimentos circulares. O mesmo procedimento foi realizado para os espaços $\mathrm{A}$ e $\mathrm{B}$ e o cartão foi completamente homogeneizado com movimentos circulares por 2 minutos, sendo que antes, mais uma gota $(40 \mathrm{~mL})$ de solução PBS foi adicionada ao espaço A. Ao final do tempo, a leitura do resultado foi realizada observando a presença de aglutinação ou não em cada espaço. O cartão foi colocado em ângulo de $45^{\circ}$, o excesso da solução de cada espaço foi retirado com uma bolsa dessecante e o cartão foi deixado para secar ao ar como registro permanente do animal.

A tipagem em tubo de ensaio foi realizada de acordo com trabalhos prévios. ${ }^{5,6,11}$ As amostras de sangue com EDTA foram centrifugadas para separação do plasma. O plasma e a capa leucocitária foram retirados e o concentrado de eritrócitos foi submetido a três lavagens consecutivas com PBS (tampão fosfato - pH
7,2), centrifugação a 3500 rpm (rotações por minuto), durante 5 minutos. Logo após a última lavagem, uma suspensão de hemácias a $5 \%$ foi preparada $(50 \mathrm{~mL}$ do concentrado de eritrócitos diluídos em $950 \mathrm{~mL}$ de PBS). Em seguida, $50 \mathrm{~mL}$ de PBS (tubo C controle), $50 \mathrm{~mL}$ do soro anti-A (tubo A) e $50 \mathrm{~mL}$ da solução anti-B preparada com Triticum vulgaris (tubo B) foram colocados em três tubos diferentes e $25 \mathrm{~mL}$ da suspensão de eritrócitos adicionados a cada tubo e homogeneizados suavemente. Após 15 minutos de incubação à temperatura ambiente, os tubos foram centrifugados por 15 segundos a $3500 \mathrm{rpm}$ (aproximadamente 1260 g). Finalmente, a leitura do resultado foi realizada ressuspendendo as células e observando-se a presença de aglutinação.

A tipagem reversa foi realizada em todas as amostras, o que consiste em um procedimento similar ao da tipagem, porém o soro de cada animal foi incubado com a suspensão de células de gatos de tipo A e B conhecidos para confirmação da presença de aloanticorpos. ${ }^{4}$

\section{Resultados e Discussão}

Neste estudo, foram encontrados $97 \%$ de gatos do tipo sangüíneo A e 3\% do tipo B (dois machos e uma fêmea). Não foram encontrados gatos do tipo sangüíneo AB. As figuras 1 e 2 mostram a leitura dos resultados para os tipos A e B, respectivamente. A figura 3 mostra o teste em tubo de ensaio para confirmação de gatos tipo $\mathrm{B}$.

A distribuição dos tipos sangüíneos varia de acordo com a região geográfica e entre as diferentes raças de felinos, mas pouco se sabe sobre os felinos do Brasil. . $^{13,14,16}$ De acordo com os resultados obtidos neste estudo, foi observado que na cidade de Porto Alegre, coincidindo com estudos realizados em outras regiões do país e outros países (Tabela 2), o tipo sangüíneo A é o de maior prevalência na população de gatos mestiços, este fato pode estar relacionado com a maior predominância de gatos homozigotos para o alelo A. 


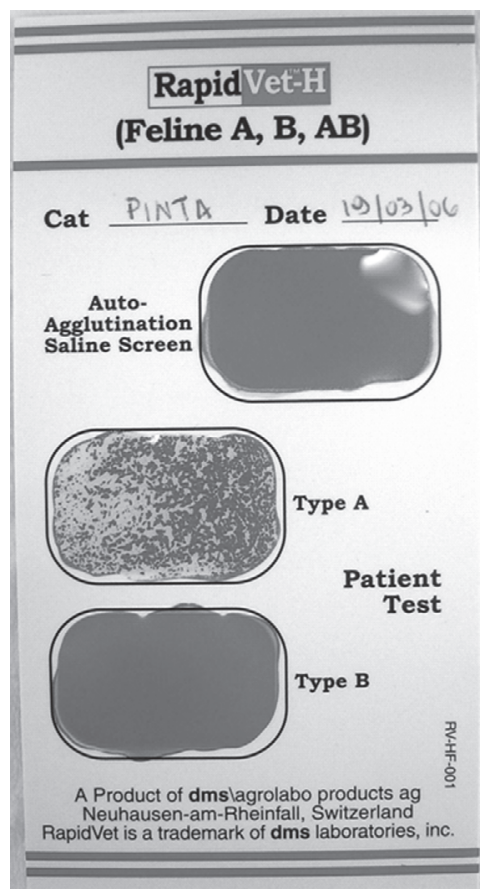

Figura 1 - Tipagem em cartão de gato de tipo sangüíneo A

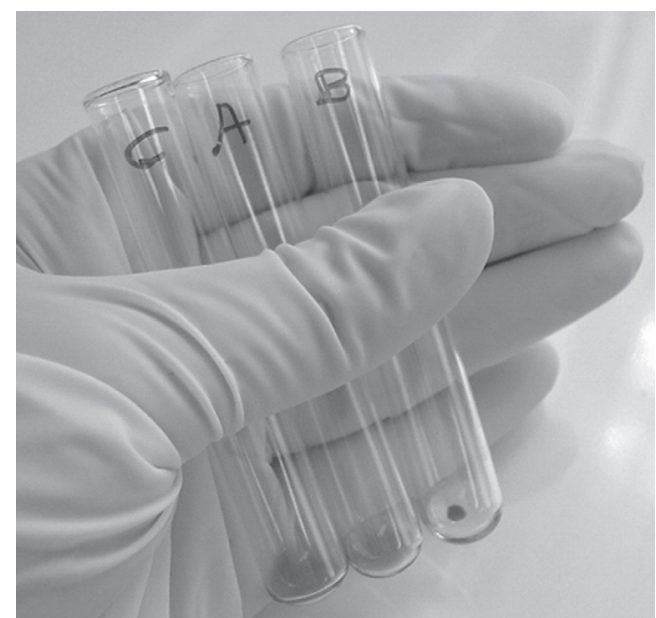

Figura 3 - Tipagem em tubo de ensaio para confirmação de gato do tipo sangüíneo $B$ (tubo $C$ - controle tubo A - soro anti-A; tubo B - lectina anti-B)

A prevalência do tipo sangüíneo $B$ encontrada no presente estudo (3\%), está de acordo com a maior parte dos estudos realizados até hoje no mundo, este fato também pode estar relacionado com a maior predominância de gatos homozigotos para o alelo A. ${ }^{4} \mathrm{Na}$ Europa, a prevalência de gatos tipo B varia de $0,4 \%$ a $14,9 \% .{ }^{11} \mathrm{Na}$ América Latina, o estudo realizado na Argentina, revelou uma

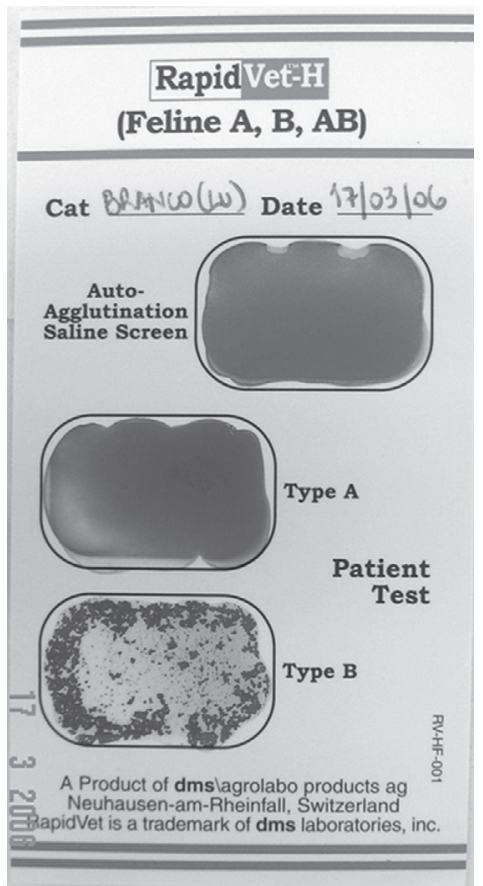

Figura 2 - Tipagem em cartão de gato de tipo sangüíneo B

prevalência de 2,6\% de gatos do tipo B e $1,3 \%$ de gatos do tipo AB. ${ }^{17}$ Nos Estados Unidos, a prevalência de gatos de tipo $\mathrm{B}$ é de $1,7 \% .{ }^{4}$ Uma alta prevalência $(36 \%)$ de gatos tipo $\mathrm{B}$ foi encontrada na Austrália. ${ }^{9}$

Neste estudo, não foram encontrados gatos do tipo $A B$, fato que pode estar associado ao cruzamento de raças presentes no Brasil com baixa prevalência do alelo $A B \cdot{ }^{4} \mathrm{~A}$ prevalência do tipo $A B$ parece ser muito baixa no mundo todo (Tabelas 1 e 2). Entretanto, pesquisadores do Reino Unido encontraram uma prevalência de $5 \%$ do tipo $\mathrm{AB}$ em gatos mestiços e de $5,3 \%$ em gatos de raça. ${ }^{11}$ Tem sido sugerido que o tipo sangüíneo $A B$ pode ser causado por um terceiro alelo que permite a expressão codominante dos antígenos A e B. ${ }^{4,9,18}$ Diferenças na prevalência dos tipos sangüíneos têm sido observadas em gatos mestiços em diferentes países (Tabela 2).

Um estudo na cidade do Rio de Janeiro (RJ), com 48 gatos domésticos sem distinção de raça, revelou uma prevalência de $93,75 \%$ de gatos do tipo 
Tabela 2 - Prevalência dos tipos sangüíneos em gatos domésticos mestiços em diferentes países

\begin{tabular}{|c|c|c|c|c|}
\hline País (cidade ou região) & $\mathbf{n}$ & $\begin{array}{c}\text { Tipo A } \\
(\%)\end{array}$ & $\begin{array}{c}\text { Tipo B } \\
(\%)\end{array}$ & $\begin{array}{c}\text { Tipo AB } \\
(\%)\end{array}$ \\
\hline Alemanha ${ }^{12}$ & 404 & 94,1 & 5,9 & 0 \\
\hline Argentina (Buenos Aires) $)^{17}$ & 76 & 96,1 & 2,6 & 1,3 \\
\hline Austrália (Sydney) ${ }^{10}$ & 186 & 62,0 & 36,0 & 1,6 \\
\hline Brasil (Salvador) ${ }^{13}$ & 58 & 93,3 & 6,7 & 0,0 \\
\hline Brasil (Porto Alegre) ${ }^{14}$ & 105 & 97,1 & 1,9 & 1,0 \\
\hline Espanha (Bracelona) ${ }^{19}$ & 100 & 94 & 5 & 1 \\
\hline $\mathrm{EUA}^{4}$ & 1072 & 99,72 & 0,28 & 0,0 \\
\hline Gran Canária ${ }^{20}$ & 97 & 88,7 & 7,2 & 4,1 \\
\hline Grécia $^{21}$ & 207 & 78,3 & 20,3 & 1,4 \\
\hline Inglaterra $^{22}$ & 105 & 67,6 & 30,5 & 1,9 \\
\hline Japão 23 & 238 & 89,9 & 0,9 & 9,2 \\
\hline Portugal $^{15}$ & 159 & 89,3 & 4,4 & 6,3 \\
\hline Reino Unido ${ }^{11}$ & 139 & 87,1 & 7,9 & 5 \\
\hline Turquia $^{18}$ & 301 & 73,1 & 24,6 & 2,3 \\
\hline
\end{tabular}

Nota: $\mathrm{n}=$ número de gatos testados; $\%=$ porcentagem de gatos

A, nenhum do tipo $\mathrm{B}$ e $6,25 \%$ do tipo AB. ${ }^{16}$ Estes dados confirmam a maior prevalência do tipo sangüíneo A em felinos domésticos do Brasil, mas diferem em relação aos tipos sangüíneos $\mathrm{B}$ e $\mathrm{AB}$. A prevalência do tipo $A B$ na cidade do Rio de Janeiro parece ser maior do que na cidade de Porto Alegre e em outros países, como demonstrado na tabela 2 .

Até o momento, o número de animais (mestiços e de raça) avaliados no Brasil ainda é pequeno, quando comparado com a população brasileira de gatos domésticos, são necessários mais estudos para que se possa conhecer a prevalência dos tipos sangüíneos em cada raça e em cada região do país.

\section{Conclusões}

O presente estudo indica que em Porto Alegre há uma maior prevalência de gatos mestiços do tipo A, entretanto a prevalência de gatos do tipo B encontrada no trabalho é mais alta do que aquelas relatadas em alguns países. $O$ conhecimento da prevalência dos tipos sangüíneos da população de gatos de uma região pode auxiliar na determinação dos riscos de reações transfusionais e de ocorrência de isoeritrólise neonatal, estes podem ser prevenidos através de tipagem sangüínea e do teste de compatibilidade sangüínea.

\section{Agradecimentos}

Os autores agradecem à Empresa DMS Laboratories pelo fornecimento dos kits Feline RapidVet-H para tipagem sangüínea, à Universidade da Pensilvânia (EUA) por fornecer os anti-soros para teste de confirmação de tipagem sangüínea e à Empresa BD Vacutainer Brasil por fornecer os tubos e material para coleta das amostras de sangue. 


\section{Prevalence of blood types $A, B$ and $A B$ in mixed breed domestic cats of Porto Alegre, Rio Grande do Sul, Brazil}

\section{Abstract}

The present study was carried out to determine the prevalence of the blood types in mixed breed domestic cats of Porto Alegre, Rio Grande do Sul, Brasil. A hundred of clinically healthy mixed breed and nonrelated cats were selected. Blood samples were collected from the jugular vein and the blood typing was performed by RapidVet H Feline test (DMS Laboratories, Flemington, USA) and by hemagglutination tube test. Reverse blood typing was done to confirm the blood types and the presence of alloantibodies. In the present study the prevalence of blood type A and B in cats were $97 \%$ and $3 \%$, respectively. No AB blood type cats were found. These results indicate that there is a high prevalence of blood type A mixed breed domestic cats in the south of Brazil, although the prevalence o B cats found is higher than reported in some countries. The knowledge of feline blood types prevalence in cat population can help to determine the risks of transfusion reactions and neonatal isoerythrolysis, and these can be avoid by blood typing and cross-matching test.

\section{Referências}

1 HARVEY, J. W. The erythrocyte: physiology, metabolism and biochemical disorders. In: KANEKO, J. J.; HARVEY, J. W.; BRUSS, M. L. Clinical biochemistry of domestic animals. 5. ed. San Diego: Academic Press USA, 1997. cap.7, p. 157-203.

2 HOHENHAUS, A. E. Importance of blood groups and blood group antibodies in companion animals. Transfusion Medicine Reviews, v. 18, n. 2, p. 117126, 2004.

3 WEINSTEIN, N. M.; BLAIS, M. C.; HARRIS, K.; OAKLEY, D. A.; ARONSON, L. R.; GIGER, U. A newly recognized blood group in domestic shorthair cats: the Mik red cell antigen. Journal of Veterinary Internal Medicine, v. 21, n. 2, p. 287-292, 2007.

4 GIGER, U.; BÜCHELER, J.; PATTERSON, D. F. Frequency and inheritance of $\mathrm{A}$ and $\mathrm{B}$ blood types in feline breeds of the United States. Journal of Heredity, v. 82, n. 1, p. 15-20, 1991.

5 KNOTTENBELT, C. M. The feline AB blood group system and its importance in transfusion medicine. Journal of Feline Medicine and Surgery, v. 4, n. 2, p. 69-76, 2002.

6 STIEGER, K.; PALOS, H.; GIGER, U. Comparison of various blood-typing methods for the feline $A B$ blood group system. American Journal of Veterinary Research, v. 66, n. 8, p. 1393-1399, 2005.

7 SPARKES, A.; GRYFFYDD-JONES, T. Blood groups in cats. In: DAY, M.; MACKIN, A.; LITTLEWOOD, J. Manual of canine and feline haematology and transfusion medicine. 1. ed. Hampshire: BSAVA, 2000.
Key words: Immunohematology. Blood types. Cats.

\section{p. 305-307.}

8 GRIOT-WENK, M. E.; GIGER, U. Feline transfusion medicine. Blood types and their clinical importance. Veterinary Clinics of North America: small animal practice, v. 25, n. 6, p. 1305-1322, 1995.

9 MALIK, R.; GRIFFIN, D. L.; WHITE, J. D.; ROZMANEC, M.; TISDALL, P. L.; FOSTER, S. F.; BELL K.; NICHOLAS, F. W. The prevalence of feline A/B blood types in the Sydney region. Australian Veterinary Journal, v. 83, n. 1-2, p. 38-44, 2005.

10 ARIKAN, S.; DURU, S. Y.; GURKAN, M.; AGAOGLU, Z. T. GIGER, U. Blood type $A$ and $B$ frequencies in Turkish Van and Angora cats in Turkey. Journal of Veterinary Medical Science, v. 50, n. 6, p. 303-306, 2003.

11 KNOTTENBELT, C. M.; ADDIE, D. D.; DAY, M. J.; MACKIN, A. J. Determination of the prevalence of feline blood types in the UK. Journal of Small Animal Practice, v. 40, n. 3, p. 115-118, 1999.

12 HAARER, M.; GRÜNBAUM, E.G. Blutgruppenserologische Untersuchungen bei Katzen in Deutschland. Kleintierpraxis, v. 38, p. 195-204, 1993.

13 SOUZA, V. M. M. Tipagem sanguínea em felinos no município de Salvador, 1998. 22 f. Monografia (Conclusão de curso) - Escola de Medicina de Veterinária, Universidade Federal da Bahia, Bahia, 1998.

14 GUERRA, T. A.; LACERDA, L.; OLIVEIRA, S. T.; ESTEVES, V. S.; GONZALEZ, F. H. D. Tipagem sabgüínea: 148 gatos domésticos na rotina laboratorial do LACvet - UFRGS. Acta Scientiae Veterinariae, v. 35, n. 2, p. s573-s574, 2007. 
15 SILVESTRE-FERREIRA, A. C.; PASTOR, J.; ALMEIDA, O.; MONTOYA, A. Frequencies of feline blood types in northern Portugal. Veterinary Clinical Pathology, v. 33, n. 4, p. 240-243, 2004.

16 VILAR, T. D. Tipagem sangüínea em gatos - Estudo da prevalência dos antígenos eritrocitários do sistema AB Felino utilizando metodologia gel-teste no estado do Rio de Janeiro, Brasil. Nosso Clínico, n. 54, p. 2831, 2006.

17 JACOMET, L.; MONTORO, A.; RIVERO, M.; GIGER, U. Frecuencia de los distintos grupos sanguineos en gatos de Buenos Aires, Argentina. Revista de Medicina Veterinaria, v. 78, n. 6, p. 428431, 1997.

18 ARIKAN, S.; GURKAN, M.; OZAYTEKIN, E.; DODURKA, T.; GIGER, U. Frequencies of blood type $\mathrm{A}, \mathrm{B}$ and $\mathrm{AB}$ in non-pedigree domestic cats in Turkey. Journal of Small Animal Practice, v. 47, n. 1, p. 10-13, 2006.

19 RUIZ DE GOPEGUI, R.; VELASQUEZ, M.; ESPADA, $Y$. Survey of feline blood types in the Barcelona area of
Spain. Veterinary Record, v. 154, n. 25, p. 794-795, 2004.

20 SILVESTRE-FERREIRA, A. C.; PASTOR, J.; SOUSA, A. P.; PIRES, M. J.; MORALES, M.; ABREU, Z.; MONTOYA, J. A. Blood types in the non-pedigree cat population of Gran Canaria. Veterinary Record, v. 155, n. 24, p. 778-779, 2004.

21 MYLONAKIS, M. E.; KOUTINAS, A. F.; SARIDOMICHELAKIS, M.; LEONTIDIS, L.; PAPADOGIANNAKIS, M.; PLEVRAKI, K. Determination of the prevalence of blood types in the non-pedigree feline population in Greece. Veterinary Record, v. 149, n. 7, p. 213-214, 2001.

22 FORCADA, Y.; GUITIAN, J.; GIBSON, G. Frequencies of feline blood types at a referral hospital in the south east of England. Journal of Small Animal Practice, v. 48, n. 10, p. 570-573, 2007.

23 EJIMA, H.; KUROKAWA, K.; IKEMOTO, S. Feline red blood cell groups detected by naturally occurring isoantibody. Japanese Journal of Veterinary Science, $v$. 48, n. 5, p. 971-976, 1986. 